\title{
Development of compositions from waste of polypropylene and polyethylene terephthalate and research of their technological and thermal properties
}

\author{
Bahodir Mukhiddinov ${ }^{*}$, Lola Tilavova, and Shokhruh Juraev \\ Navoi State Mining Insitute, Navoi, Uzbekistan
}

\begin{abstract}
The article presents the results of determining the melting point and the melt flow rate, Vicat heat resistance of a composition made of polypropylene waste from the study of polyethylene terephthalate. It has been established that with an increase in the content of polyethylene terephthalate, the melting point and heat resistance according to Vicat increase, and the melt flow rate of the compositions decreases. The Hildebrand solubility parameters and the packing density of macromolecules are calculated using the increment method. The thermal characteristics of the compositions were investigated by the derivatography method. Their decomposition onset temperature, decomposition rate, and the amount of energy consumed for the decomposition of polymers and polymer compositions were determined. It was revealed that the compositions of polyethylene terephthalate with secondary polypropylene are more thermostable than compositions of polyethylene terephthalate with primary polypropylene.
\end{abstract}

\section{Introduction}

In 2020, the volume of polymer consumption in the world exceeded 265 million tons. The largest share of consumption falls on polyethylene of 100.0 million tons, in the second place is polypropylene of 72.0 million tons, in the third place is polyvinyl chloride of 46.0 million tons. Polystyrene and acrylonitrile butadiene styrene (ABS) plastics account for about 23.0 million tons of global demand [1-9].

According to forecasts, the demand for polymers will increase markedly in the coming years. The highest growth rates are expected in the segment of polyethylene terephthalate (PET) and propylene polymers. At the same time, the development of the market for polystyrene plastics and polyvinyl chloride will slow down. In the period up to 2021 , the average annual growth rate of demand for polyethylene terephthalate may exceed $5 \%$, the market capacity - close to 90 million tons. Drivers of growth in demand for food grade PET are the growing need for pure natural bottled water against the backdrop of the growing

\footnotetext{
*Corresponding author: muhiddinov.b@mail.ru
} 
popularity of a healthy lifestyle and deteriorating drinking water quality, an increase in the demand for light packaging, etc.

Currently, the Republic of Uzbekistan produces polyethylene, polypropylene and polyvinyl chloride, and composite materials based on them.

Uz-Kor Gas Chemical was commissioned in 2016 for the production of polyethylene and polypropylene. According to Polyglobe, PIE (www.polyglobe.ru) has a production capacity for the production of ethylene 400 thousand tons per year, high-density polyethylene (HDPE) 387 thousand tons per year, propylene and polypropylene (PP) 83 thousand tons per year and 100 thousand tons per year of PVC in Navoiazot JSC. Shurtan GCC has a production capacity to produce HDPE and LLDPE in the amount of 125 thousand tons per year [6, 7].

Among the large-tonnage polymeric materials, polyethylene terephthalate (PET), PE and PP are important. According to the data of 2018, the output of primary PET for bottle use exceeded 21 million tons. According to experts, the total number of PET bottles produced in the form of bottles exceeds more than 500 billion pieces $[1,6]$.

It is known that polypropylene is mainly used as packaging and bags for transporting cement, flour and other industrial goods. Therefore, recycling PET and PP waste and obtaining products based on them is an urgent problem from ecology and economics.[10$16]$.

\section{Materials and Methods}

The object of the study was polyethylene terephthalate (PET), obtained from used plastic bottles for drinks, which were crushed with a knife crusher. The size of PET flakes was 5$10 \mathrm{~mm}$, while the bulk density is $200-300 \mathrm{~kg} / \mathrm{m}^{3}$. Used polypropylene (primary) grade $\mathrm{J}$ $550 \mathrm{~S}$ synthesized in the Uz-Kor Gas Chemical complex and secondary polypropylene used as bags for transporting flour.

Compositions of PP with PET were prepared in a screw extruder in the temperature range $170-265^{\circ} \mathrm{C}$ with a screw rotation of $31 \mathrm{rpm}$, with a certain PTFE: PP ratio. They were first mechanically mixed, then passed through a screw extruder. The resulting molten mixture was passed through a granulator after cooling. Then the resulting pellet was passed 3-4 times through an extruder under the same conditions for uniform distribution of PET: PP components.

Derivatographic analysis of the samples was carried out on a Labsys evo SETARAM TG DTA DSC +1600 instrument in the temperature range $30-700^{\circ} \mathrm{C}$ at a heating rate of 5 $\mathrm{deg} / \mathrm{min}$. The melt flow rate was determined by the method [17].

\section{Results and Discussion}

Thermoplastic polymeric materials are processed into products mainly in the molten state. The characteristics of the melt of polymeric materials are evaluated by the value of the melting point (Tm) and the melt flow rate (MFR).

We carried out experiments to determine the melt flow rate under standard conditions, the results of which are shown in Table 1. 
Table 1. Effect of PET content on the melt flow rate (MFR), melt viscosity, melting point (Tm.) And Vicat heat resistance of polypropylene

\begin{tabular}{|c|c|c|c|c|c|c|c|}
\hline \multirow{2}{*}{ Indicators } & PP & \multicolumn{5}{|c|}{ PET content, mass. $\%$} & PET \\
\hline & 100 & 5 & 10 & 15 & 20 & 30 & 100 \\
\hline $\begin{array}{c}\text { PTR, } \\
\text { g/10 min }\end{array}$ & 4.0 & 3.7 & 3.4 & 3.1 & 2.7 & 2.3 & 3.9 \\
\hline $\begin{array}{c}\text { Viscosity } \\
\text { Melt } \mathrm{Pa} \cdot \mathrm{C} \cdot 10^{-3}\end{array}$ & 24786 & 26795.6 & 29160.0 & 31981.9 & 36720.0 & 43106.1 & 36277 \\
\hline $\mathrm{T}_{m .},{ }^{\circ} \mathrm{C}$ & 145 & 149 & 153 & 156 & 161 & 166 & 251 \\
\hline $\begin{array}{c}\text { Vicat Heat } \\
\text { Resistance, }{ }^{\circ} \mathrm{C}\end{array}$ & 145.0 & 146.4 & 148.0 & 149.7 & 155.5 & 167.0 & 192 \\
\hline
\end{tabular}

As the results of the study show (Table 1), with the addition of polyethylene terephthalate waste to the polypropylene composition, the value of the melt flow rate decreases slightly. For example, adding 10 and 20 mass. \% waste (secondary) PET, respectively, is reduced from $3.4 \mathrm{~g} / 10 \mathrm{~min}$ to $2.7 \mathrm{~g} / 10 \mathrm{~min}$. This is the value of the initial polymers PP-11.0 and for PET $3.9 \mathrm{~g} / 10 \mathrm{~min}$.

The effective viscosity of the melt was calculated [18], the results of which are given in Table 1. According to the value of the melt flow index (Table 1), with a decrease in the MFI value, the melt viscosity of the compositions increases. This is due to a decrease in intermolecular interactions in polymer macromolecules.

We also determined the melting points of the starting polymers (PP, PET) and their compositions, the results of which are shown in Table.1.

The results of the study show (Table 1) that with an increase in the PET content in the PP composition, the melting point of PP composites increases. For example, and with a content of 10 and 20 mass. \% PET TPL. polypropylene is 153 and $161{ }^{\circ} \mathrm{C}$, respectively.

We also used the method of increments, which establishes a relationship between the melting point and the structure, i.e. Van der Waals volumes of the repeating unit of the polymer:

$$
\mathrm{T}_{\mathrm{m}}=\frac{\Sigma_{i} \Delta \mathrm{V}_{\mathrm{i}}}{\Sigma_{i} \mathrm{~K}_{\mathrm{i}} \Delta \mathrm{V}_{\mathrm{i}}}
$$

Where, $\mathrm{K}_{\mathrm{i}}$ is parameter characteristic of each atom and the type of intermolecular interaction.

$\Sigma_{\mathrm{i}} \Delta \mathrm{V}_{\mathrm{i}}$ is Van der Waals molar volume of a repeating unit of a polymer.

To calculate $T_{m}$ composition, it is convenient to use a ratio expressed through the melting point of individual homopolymers [19];

$$
\mathrm{T}_{m}=\frac{\alpha_{1}\left\{\left(\Sigma_{i} \Delta V_{i}\right)_{1}-\left(\Sigma \Delta V_{i}\right)_{2}+\left(\Sigma_{\mathrm{i}} \Delta \mathrm{V}_{\mathrm{i}}\right)_{2}\right\}}{\alpha_{1}\left\{\frac{\left(\Sigma_{\mathrm{i}} \Delta \mathrm{V}_{\mathrm{i}}\right)_{1}}{T_{m 1}}-(\Sigma)\right\}}
$$

where, $\alpha_{1}$ is mole fraction of the first component; $T_{m 1}$ and $T_{m 2}$ is melting point of individual homopolymers.

The additive dependence of the melting point of the composition, polypropylene, on the composition, calculated by the equation, is in sufficient agreement with the experimental data (Table 2). This is apparently due to an additive change in the intermolecular interactions of homopolymers in the composition.

One of the parameters characterizing the practical application of polymeric materials is heat resistance. Table 1 shows the data on the heat resistance of PP-PET composites estimated by the Vicat method. As can be seen from Table 1, the heat resistance of PP 
composites regularly increases. This is obviously due to a slight increase in the intermolecular interaction of PP macromolecules with PET.

The temperature of the onset of decomposition of polymers and its compositions $\left(\mathrm{T}_{\text {o.d. }}\right)$, the molecular packing coefficient and the Hildebrand solubility parameter were also calculated by the method of increments, the results of which are presented in Table 2.

Table 2. Experimental and calculated values of the thermophysical characteristics of homopolymers (polypropylene and polyethylene terephthalate) and their compositions

\begin{tabular}{|c|c|c|c|c|c|c|c|c|}
\hline No. & $\begin{array}{c}\text { Compositions } \\
\text { PET content, } \\
\text { mass.\% }\end{array}$ & \multicolumn{2}{|c|}{$\mathrm{T}_{\mathrm{m}},{ }^{\circ} \mathrm{C}$} & \multicolumn{2}{|c|}{$\mathrm{T}_{\text {o.d. }}{ }^{\circ} \mathrm{C}$} & $\begin{array}{c}\text { Polymer } \\
\text { density, } \\
\text { g/cm }\end{array}$ \\
\cline { 3 - 6 } & & Exp. & Calc. & Exp. & Calc. & $\begin{array}{c}\text { Molecular } \\
\text { packing } \\
\text { ratio, } \\
\text { (calc.) }\end{array}$ & $\begin{array}{c}\text { Hildebrand } \\
\text { solubility } \\
\text { parameter } \\
\text { cal/cm }\end{array}$ \\
\hline 1 & $0($ PP) & 145 & 137 & 296 & 431 & 0.9371 & 0.689 & 10.7 \\
\hline 2 & 5 & 149 & 155 & 288 & 429 & 0.9592 & 0.679 & 10.6 \\
\hline 3 & 10 & 153 & 169 & 286 & 420 & 0.9815 & 0.649 & 10.5 \\
\hline 4 & 15 & 156 & 180 & 279 & 416 & 1.0036 & 0.634 & 10.4 \\
\hline 5 & 20 & 161 & 188 & 274 & 428 & 1.0258 & 0.629 & 10.3 \\
\hline 6 & 30 & 166 & 202 & 272 & 435 & 1.0702 & 0.621 & 10.2 \\
\hline 7 & $100($ PET) & 251 & 242 & 315 & 399 & 1.3807 & 0.693 & 10.1 \\
\hline
\end{tabular}

To predict the solubility of a polymer in various organic solvents and to preliminary estimate the compatibility of polymers with each other, such characteristic as the solubility parameter is often used.

The Hildebrand solubility parameter $(\delta)$ was determined [20]:

It is known that as the $\delta$ value increases, the compatibility and solubility of the polymer improves. Analyzing the data obtained, table. 2, we conclude that an increase in the composition of PP PET leads to an increase in the value of $\delta$, which leads to an improvement in the compatibility.

A measure of the packing density of macromolecules is the molecular packing coefficient $\mathrm{K}$, which was determined [21, 22]:

As can be seen from the study results (Table 2), with an increase in the PET content, the molecular packing coefficient decreases, which is associated with a great difference in van der Waals volumes and creates free volumes when packing macromolecules.

Thus, by calculating the value of the molecular packing coefficient and the Hildebrand solubility parameter, one can predict the density of the polymer, the solubility and compatibility of polymers with each other and their composition.

The thermal properties of the developed compositions based on polyethylene terephthalate and polypropylene wastes were studied by derivatography. In fig. 1 shows the results of the analysis of dynamic thermogravimetric curves (DTGA), the products of thermogravimetry (TGP) and differential scanning calorimetry (DSC) of the polyethylene terephthalate composition with secondary polypropylene.

Analysis of the results of the study of DTGA curves in Fig. 1 shows that the curve consists mainly of one sigmoid, the process of which occurs in one stage. The process mainly occurs in the temperature range from $260{ }^{\circ} \mathrm{C}$ to $455^{\circ} \mathrm{C}$, while the weight loss is $80.34 \%$. Intensive decomposition occurs at a temperature of $430{ }^{\circ} \mathrm{C}$, with a weight loss of $75.50 \%$.

Decomposition begins mainly at $100{ }^{\circ} \mathrm{C}$ for the starting polymers PET and PE, which amount to 5.49 and $0.65 \mathrm{wt} \%$, respectively. With increasing temperature, the rate of decomposition of the starting polymers increases. 


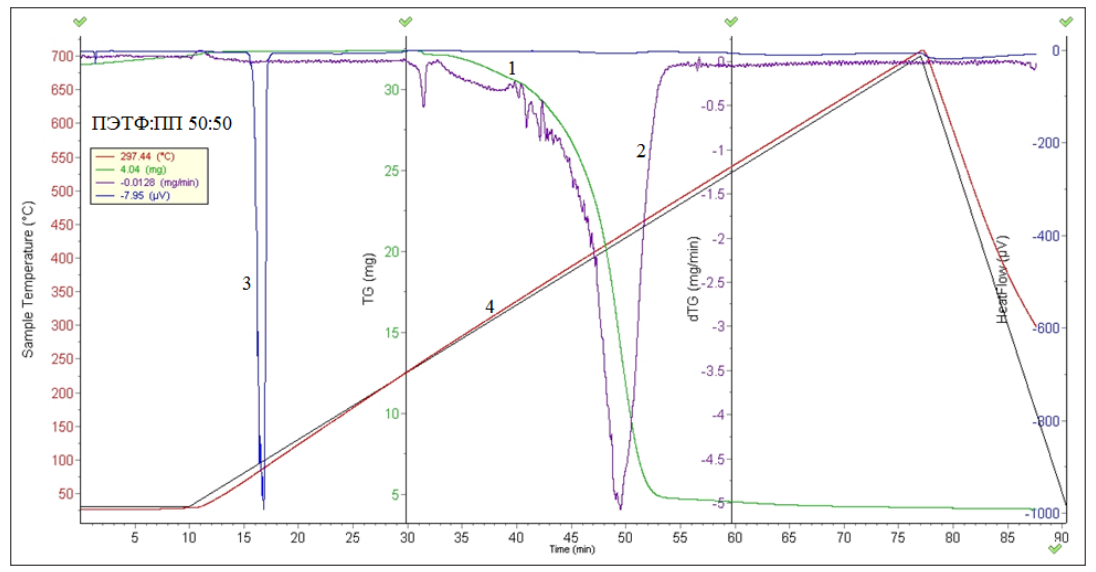

Fig. 1. Derivatogram of compositions of polyethylene terephthalate with secondary polypropylene PET: PPvtor. 50:50 (1 is DTGA curve; 2 is TGP curve; 3 is DSC curve; 4 is temperature curve (line))

Intensive decomposition of polymers mainly occurs after $300{ }^{\circ} \mathrm{C}$ and reaches a maximum at $420-460{ }^{\circ} \mathrm{C}$, while the weight loss for PET is $61.78 \mathrm{wt} . \%$ And $98.50 \mathrm{wt} . \%$, And for PP it is $7.87 \mathrm{wt} \% \%$ And $48,50 \mathrm{wt} . \%$, respectively. It follows that polypropylene is much more thermally stable than polyethylene terephthalate during thermal-oxidative degradation.

Comparison of the research results (Fig. 1, Table 3) shows that when polypropylene is introduced into the PET composition, the thermal stability of the composition changes extremely. For example, compositions of polyethylene terephthalate containing 10; thirty; fifty; 70 and 90 wt.\% Polypropylene, the thermal stability of the composition with an increase in the content of the latter at $450^{\circ} \mathrm{C}$ is $74.16 ; 84.19 ; 77.52 ; 76.26$ and $88.97 \mathrm{wt} \%$, respectively. From the analysis of the research results, it can be seen that first, the thermal stability of the composition decreases to PET: PE 50:50 $77.52 \mathrm{wt} \%$, and then increases again. This is apparently because an increase in the content of polyethylene terephthalate, leading to a decrease in the thermal stability of the composition, is associated with the intensifying effect of the decomposition products of polyethylene terephthalate during the thermal decomposition of the composition.

The DSC curves of the initial PP and PET compositions with polypropylene. Analysis of the DSC curve of the initial PP (Fig. 2) shows that it consists of five endothermic and five exothermic peaks.

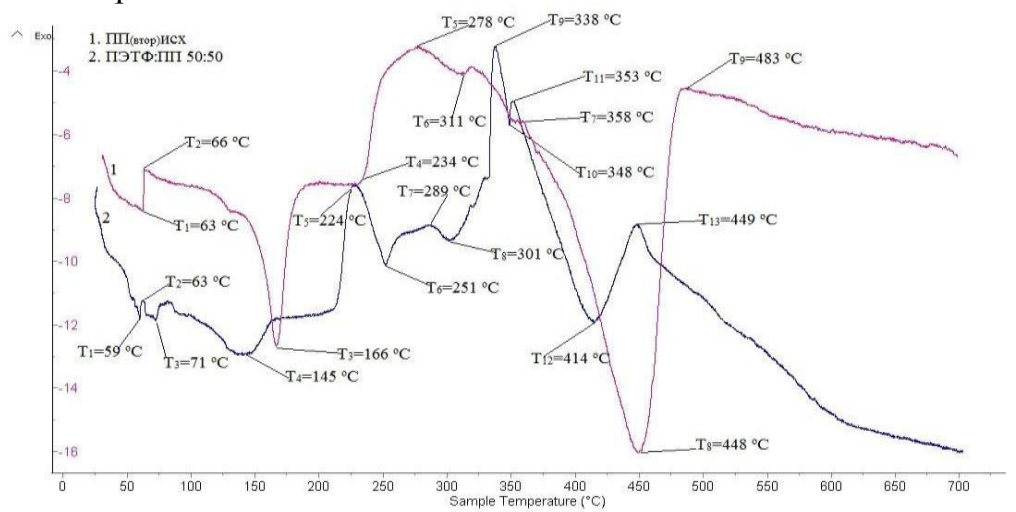

Fig. 2. DSC curves of the initial recycled polypropylene (1) and composites of polyethylene tetrafluoroethylene with recycled polypropylene PET: PP (2) 
The first peak at a temperature of $145{ }^{\circ} \mathrm{C}$ refers to the melting of the crystalline regions of PP. The endothermic effects at temperatures of $234^{\circ} \mathrm{C}, 3110^{\circ} \mathrm{C}, 3530{ }^{\circ} \mathrm{C}$, and $448{ }^{\circ} \mathrm{C}$, this apparently refers to the onset of the oxidation temperature. At temperatures of $3530^{\circ} \mathrm{C}$ and $483{ }^{\circ} \mathrm{C}$, thermal-oxidative destruction occurs with rupture of weak carbon-carbon bonds. The endothermic peak at $448^{\circ} \mathrm{C}$ can be associated with the depolymerization of polypropylene with the formation of propylene. And the exothermic peaks at temperatures of $278{ }^{\circ} \mathrm{C}, 353{ }^{\circ} \mathrm{C}$ and $4830{ }^{\circ} \mathrm{C}$ are due to thermal-oxidative destruction of the polymer.

From the analysis of the DSC curve of the PET-PP composition (Fig. 2, curve 2), it can be seen that the curve consists mainly of five endothermic and three exothermic peaks. The first and second peak temperatures at $145{ }^{\circ} \mathrm{C}$ and $251{ }^{\circ} \mathrm{C}$ refers to the melting of the crystalline regions of PP and PET, respectively.

And exothermic peaks at temperatures of $224{ }^{\circ} \mathrm{C}, 289^{\circ} \mathrm{C}, 338^{\circ} \mathrm{C}, 353^{\circ} \mathrm{C}$ and $449^{\circ} \mathrm{C}$ are characteristic of thermo-oxidative destruction of the polymer composition.

To compare the thermal stability of the polyethylene terephthalate composition with primary and secondary polypropylene (Table 3 ), we studied the dynamic thermogravimetric analysis of the composition.

The temperature of the beginning of decomposition was determined. It corresponds to $\mathrm{T}_{10}$ temperature 10 and $\mathrm{T}_{20} 20 \%$ weight loss and $\mathrm{T}_{50}$ (ipdt) - temperature called "Integral procedural decomposition temperature", corresponding to $50 \%$ weight loss.

Table 3.Results of dynamic thermogravimetric analysis of PET: PP (primary) and PET: PP (secondary) compositions

\begin{tabular}{|c|c|c|c|c|c|c|}
\hline \multirow{2}{*}{ Samples } & \multicolumn{9}{|c|}{ Decomposition temperature, ${ }^{\circ} \mathrm{C}$} & \multicolumn{2}{c|}{$\begin{array}{c}\text { Weight loss at } \\
\text { a specific } \\
\text { temperature, } \%\end{array}$} \\
\cline { 2 - 7 } & $\mathrm{T}_{0}$ & $\mathrm{~T}_{10}$ & $\mathrm{~T}_{20}$ & $\mathrm{~T}_{50}(\mathrm{ipdt})$ & $\mathrm{T}_{400}$ & $\mathrm{~T}_{600}$ \\
\hline PET (ref) & 315 & 344 & 378 & 392 & 20.8 & 97.8 \\
\hline PP (per) ref & 295 & 359 & 385 & 424 & 37.96 & 98.9 \\
\hline PET: PP (first) 10:90 & 281 & 352 & 371 & 417 & 34.2 & 98.6 \\
\hline PET: PP (first) 30:70 & 268 & 347 & 363 & 403 & 34.8 & 96.4 \\
\hline PET: PP (first) 50:50 & 259 & 346 & 361 & 401 & 42.3 & 93.3 \\
\hline PET: PP (first) 70:30 & 276 & 362 & 390 & 417 & 45.3 & 87.6 \\
\hline PET: PP (first) 90:10 & 283 & 366 & 394 & 421 & 27.3 & 82.5 \\
\hline PP (sec) ref & 296 & 364 & 389 & 433 & 34.8 & 97.9 \\
\hline PET: PP (sec) 10:90 & 286 & 355 & 376 & 421 & 32.2 & 95.6 \\
\hline PET: PP (sec) 30:70 & 272 & 352 & 366 & 407 & 31.8 & 94.4 \\
\hline PET: PP (sec) 50:50 & 264 & 348 & 363 & 405 & 32.3 & 91.3 \\
\hline PET: PP (sec) 70:30 & 281 & 368 & 399 & 421 & 35.3 & 85.6 \\
\hline
\end{tabular}

Analysis of the research results shows that secondary polypropylene is thermally stable than primary polypropylene. For example, for the initial primary PP, the temperature of the beginning of decomposition is $295^{\circ} \mathrm{C}$, and the index of the secondary PP corresponds to $296^{\circ} \mathrm{C}$, from which it follows that $\mathrm{T} 0$ of the secondary PP is higher than that of the primary PP. Comparing the results of studying the composition of polyethylene terephthalate with primary and secondary polypropylenes in terms of thermal stability (Table 3), we are convinced that the compositions have an increase in thermal stability. For example, compositions containing compositions PET: PEperv. 50:50 the temperature of the onset of decomposition is $259{ }^{\circ} \mathrm{C}$, and the composition of PET: PE (sec.) Is 50:50 $264{ }^{\circ} \mathrm{C}$. By decomposition temperature $10 ; 20$ and $50 \%$ weight loss of the PET: PP composition (primary) is $346 ; 361$ and $401{ }^{\circ} \mathrm{C}$, and for the PET composition: PP (sec.) 348; 363 and 405 ${ }^{\circ} \mathrm{C}$, respectively. 
The weight loss at temperatures of 400 and $600{ }^{\circ} \mathrm{C}$ was also determined. The results show that, for the same PET: PP (primary) compositions, the weight loss is 42.30 and 93.30 mass \%, and for the PET: PP (secondary) composition, these indicators are 32.3 and 91.30 mass $\%$, respectively.

The results obtained show that compositions of polyethylene terephthalate with secondary polypropylene are more thermostable than compositions with primary polypropylene. This is apparently because in the process of processing and obtaining products from PP, light stabilizers and other additives are directly added, which increase thermal stability. Also, during operation, there is a decrease in the number of end groups and the formation of reticulated three-dimensional polymer structures, which also contributes to increased thermal stability.

\section{Conclusions}

1. Developed compositions from waste polyethylene terephthalate with primary and secondary polypropylene.

2. The melting point and the melt flow rate of the composition from the waste of polypropylene with polyethylene terephthalate were determined. It was found that with an increase in the content of polyethylene terephthalate, the melting temperature increases and the melt flow rate of the composition of polypropylene waste with polyethylene terephthalate decreases.

(3) The Hildebrand solubility parameters and the packing density of macromolecules were calculated using the incremental method. It was revealed that the values of the Hildebrand solubility parameter could be judged on the improvement in the compatibility of polymers with each other. It was also found that a decrease in the molecular packing coefficient is associated with a great difference in van der Waals volumes for PP and PET.

4. Thermal characteristics of compositions from polypropylene waste with polyethylene terephthalate were investigated by derivatography method. Their decomposition onset temperature, decomposition rate, and the amount of energy consumed for decomposition of polymers and polymer compositions were determined. It was found that polyethene terephthalate compositions with secondary polypropylene are more thermostable than compositions of polyethylene terephthalate with primary polypropylene.

\section{References}

1. Volkova A. V. Market of large-scale polymers, National Research University Higher School of Economics, Development Center. (2020).

2. Shurakov A. Plastic prospects Forecast of the development of polymer production in Russia, (2020)

3. Internet resources: https:/www.statista.com/statistics/720231/global-polyethyleneterephthalate-production-capacity-distribution-byregion/\#: :text=The $\% 20$ global $\% 20$ PET\%20resin $\% 20$ production, largest $\% 2^{\circ}$ Consumer $\% 20$ of $\% 20$ PET $\% 20$ bottles.

4. https://www.statista.com/statistics/282732/global-production-of-plastics-since1950/\#: :text=In\%202019\%2C\%20the\%20production $\% 20$ of,plastics $\% 20$ also $\% 2{ }^{\circ} \mathrm{Con}$ tinues $\% 20$ to $\% 20$ grow.

5. https://www.statista.com/statistics/720296/global-polyvinyl-chloride-market-size-intons/\#: :text=The $\% 20$ total $\% 20$ global\%20production $\% 20$ volume,to $\% 2044.3 \% 20$ milli on $\% 20$ metric $\% 20$ tons. 
6. https://www.statista.com/statistics/887934/polyvinyl-chloride-consumption-volumeworldwide/

7. https://ukrchem.dp.ua/2012/09/29/prognoz-k-2020-godu-v-mire-ozhidaetsyadvukratnyj-rost-proizvodstva-polivinilxlorida-pvx.html

8. https://www.statista.com/statistics/720296/global-polyvinyl-chloride-market-size-intons/\#: :text=The\%20total\%20global\%20production\%20volume,to\%2044.3\%20milli on $\% 20$ metric $\% 20$ tons.

9. Ivanovskiy S.K., Bakhaeva A.N., Ershova O.V., Chuprova L.V. Environmental aspects of the problem of recycling waste of polymer packaging and man-made mineral resources, Success of modern natural science. pp 813-817, (2015)

10. AS Klinkov, PS Belyaev, VG Odnolko, MV Sokolov, PV Makeev, IV Shashkov Utilization and processing of solid household waste, Tambov, Publishing house FGBOU VPO "TSTU" p.188, (2015)

11. Levin V.S., Korostelev V.I. Vtorichnoe ispolzovanie polimernyx materialov. [Recycling of polymeric materials]. Ximiya, pp 81-96. (1985)

12. Rybyanets N.M, Technology for recovery of PET manufacturing wastes into polyether resins Technol. Civil. Impact Environ .: Situat. Post-Sov. Area: Int. Symp., Karlsruhe, 22-26 Apr., 1996, p. 109. (1996,)

13. Lisenko A. M., Negmatov S. S., Salimsakov A. Yu., O problemakh razrabotki tekhnologii pererabotki gorodskikh bytovykh otkhodov, On the problems of developing a technology for processing municipal waste, Composition materiallar., (1), pp.81(2016).

14. Korostelev V.I., Levin V.S. Proizvodstvo i pererabotka plastmass i sinteticheskix smol, Production and processing of plastics and synthetic resins, Moscow, Research Institute of Technical and Economic Research in the Chemical Complex, (1). pp.3639. (1979).

15. Vilnis S.A., Vapna Yu.M. Novoe $\mathrm{v}$ texnologii poroshkovix polimernix materialov $\mathrm{i}$ pokritiy, New in technology of powder polymer materials and coatings. Leningrad, Leningrad House of Scientific and Technical Propaganda, 2, pp. 16-18. (1969).

16. GOST 11645-73. Plastics is a method for determining the melt flow rate of thermoplastics. Publishing house of standards. Moscow (1994).

17. Encyclopedia of Polymers. Ed. Soviet Encyclopedia, (1). p 844. Moscow, (1972).

18. Askadsky A.A., Matveev Yu.I., Slonimsky G.L., Korshak V.V.-DAN USSR, 238, No. (3), p. 592-595. (1978)

19. Askadsky A.A., Matveev Yu.I. Chemical structure and physical properties of polymers. Chemistry, pp. 101-110. (1983),

20. Askadsky A.A., Kondrashchenko V.I. Computer materials science of polymers. (1), Scientific world, p. 544. (1999),

21. Galperin E.L., Tsvankin D.Ya. Melting point and structure of photopolymers. Highmolecular compounds (12), Volume (A) XVIII, (1976) 